\title{
Quantitative magnetic resonance characterization of the effect of physical training on skeletal muscle of the Ts65Dn mice, a model of Down syndrome
}

\author{
Barbara Cisterna $^{1 \#}$, Pietro Bontempi ${ }^{2 \#}$, Anatoly Petrovich Sobolev ${ }^{3}$, Manuela Costanzo $^{1}$, Manuela Malatesta ${ }^{1}$, \\ Carlo Zancanaro ${ }^{1}$ \\ ${ }^{1}$ Department of Neurosciences, Biomedicine and Movement Sciences, University of Verona, Verona, Italy; ${ }^{2}$ Department of Computer Science, \\ University of Verona, Verona, Italy; ${ }^{3}$ Institute for Biological Systems, National Research Council, Rome, Italy
}

\#These authors contributed equally to this work.

Correspondence to: Manuela Malatesta. Department of Neurosciences, Biomedicine and Movement Sciences, University of Verona, 37134 Verona, Italy. Email: manuela.malatesta@univr.it.

\begin{abstract}
Down syndrome (DS) is characterized by muscle hypotonia and low muscle strength associated with motor dysfunction. Elucidation of the determinants of muscle weakness in DS would be relevant for therapeutic approaches aimed at treating/mitigating a physical disability with a strong impact on the quality of life in persons with DS. The Ts65Dn mice is a recognized mouse model of DS, with trisomic mice presenting gross motor and muscle phenotypes. The aim of this work was to assess the effect of physical exercise, a well-known tool to improve skeletal muscle condition, in the hindlimbs of trisomic and euploid male mice using quantitative magnetic resonance imaging (MRI). Magnetic resonance spectroscopy (MRS) metabolomics and histological fiber typing were used to further characterize the post-exercise muscle. Quantitative MRI showed not significantly different amounts of skeletal muscle in proximal hindlimbs in trisomic and euploid mice both at baseline and after physical exercise $(\mathrm{P}>0.05)$. Similar results were obtained for hindlimbs subfascia adipose tissue, and subcutaneous adipose tissue $(\mathrm{P}>0.05)$. MRS showed lower amounts of exercise-related metabolites (valine, isoleucine, leucine) in euploid $v s$. trisomic mice after exercise $(\mathrm{P} \leq 0.05)$. The percentage of slow-twitch fibers was similar in the two genotypes $(\mathrm{P}>0.05)$. We conclude that in DS adapted physical exercise (one month of training) does not induce quantitative changes in skeletal muscle or fiber type composition therein; however, the metabolic response of skeletal muscle to exercise may be affected by trisomy. These findings prompt further research investigating the role of physical exercise as a cue to clarify the mechanisms of the muscular deficit found in DS.
\end{abstract}

Keywords: Magnetic resonance imaging (MRI); mouse model; physical activity; nuclear magnetic resonance spectroscopy (MRS); morphometry

Submitted Jul 14, 2021. Accepted for publication Nov 12, 2021.

doi: 10.21037/qims-21-729

View this article at: https://dx.doi.org/10.21037/qims-21-729

\section{Introduction}

Down syndrome (DS) is a condition caused by a trisomy of the 21 st chromosome affecting approximately 1 out of 700 live births (1). DS is associated with, among other conditions, intellectual disability, craniofacial alterations, congenital heart disease, early-onset Alzheimer's disease, and gastrointestinal disorders. Muscle hypotonia and low muscle strength are found in persons with trisomy 21 as well, with an intellectual disability only partially explaining such a deficit (2). The Ts65Dn mouse is a murine model 
of DS presenting several phenotypes expressed in the human condition (3) inclusive of gross motor and muscle phenotypes. However, relatively little work has been done in this animal model investigating the trisomy-related muscular deficit or testing the efficacy of treatments with an aim at getting cues for treating the human DS.

Previous work from our laboratory $(4,5)$ examined the ultrastructure and metabolomics of the quadriceps muscle in sedentary euploid (SE) and trisomic Ts65Dn mice showing trisomy-associated morphological changes in mitochondria and myonuclei consistent with the multi-systemic premature aging typical of DS as well as sarcoplasmic hypertrophy of myofibers. In accordance, magnetic resonance spectroscopy (MRS) metabolomics showed, in trisomic mice, a tendency to an overall increase in muscle metabolites involved in protein synthesis. Following up on such findings, in the present work we explored in Ts65Dn mice the effect of physical exercise on the proximal hindlimb (i.e., the body segment containing the largest single mass of body skeletal muscle) using quantitative magnetic resonance imaging (MRI) (6,7). Quadriceps muscle was selected for MRS metabolomics and fiber typing evaluation because it represents a major part of the muscle mass of the proximal hindlimb, having the significantly greatest cross-sectional area in comparison with any other functional muscle group in the hindlimb (8); moreover, the quadriceps muscle is the primary mover of the hindlimb, being a primary muscle involved in gait.

Physical exercise is beneficial to optimize general and maximal muscular strength development in children and young adults with DS (9). However, direct investigation of the DS muscle status after physical training is lacking. The experiment was carried out across a large span of mouse adulthood i.e., from the consolidation of the muscular deficit (around 6 months of age) (10) to early middle-age (around 12 months), when signs of early neuromuscular senescence are not yet ensued (11).

We present the following article in accordance with the ARRIVE reporting checklist (available at https://dx.doi. org/10.21037/qims-21-729).

\section{Methods}

\section{Animals and adapted physical training protocol}

Ts65Dn [strain: B6EiC3Sn.BLia-Ts(17<16>)65Dn/DnJ] breeder mice were obtained from the Jackson Laboratory, Bar Harbor, ME, USA. Tissue for genotyping was obtained from tail clips (12) in p11 male mice. The mice were housed in groups of 3-4 by genotype and maintained under standard conditions $\left(24 \pm 1{ }^{\circ} \mathrm{C}\right.$ ambient temperature, $60 \% \pm 15 \%$ relative humidity, and $12 \mathrm{~h} \mathrm{light/dark} \mathrm{cycle)} \mathrm{and}$ fed ad libitum with standard commercial chow. The trisomic mice presented deficits in balance and motor coordination by month 4 of age (10).

The study was approved by national committee board of the Italian Ministry of Health (ref.: 538/2015-PR), in compliance with the Italian Ministry of Health (DL March 4, 2014, n. 26) and the European Communities Council (Directive 63/2010/EU of the European Parliament and of the Council) guidelines for the care and use of animals. A priori criterion of exclusion was refractoriness to running. A total of 40 animals was used for this study. A schematic overview of the whole experiment is presented in Figure 1.

For physical training, trisomic and euploid (control) mice were assigned to one of four groups: sedentary trisomic (ST; $\mathrm{n}=10)$, SE ( $\mathrm{n}=10)$, training trisomic (TT; $\mathrm{n}=10)$, and training euploid (TE; $n=10)$. Allocation of mice to the group was made with the "=Rand()" function in Microsoft Excel. Mice in the TT and TE group underwent training on a Harvard Instruments treadmill for $45 \mathrm{~min}$ a day at $8 \mathrm{~m} / \mathrm{min}$ belt speed, ( $0 \%$ incline) 5 days a week for 1 month (13). In this work, physical training was adapted to optimize trisomic mice compliance to training (13). Data were acquired at baseline and three days after completion of the experimental protocol (endpoint). Outcome assessment and data analysis were carried out in blind to mouse genetics and group.

\section{MRI and in vivo morphometry}

Images were acquired using a Bruker tomograph (Bruker, Karlsruhe, Germany) equipped with a 4.7 Tesla, 33-cm bore horizontal magnet (Oxford Ltd., Oxford, UK). Anesthetized (isofluorane) mice were placed over a heated bed into a birdcage radiofrequency coil. Relaxation time $\mathrm{T}_{2}$ was measured in the proximal hindlimb muscles with a multiecho spin-echo sequence with 16 echoes, repetition time $=2,858 \mathrm{~ms}$, echo time ranging from 11.7 to $187 \mathrm{~ms}$, field of view $=3.5 \times 3.5 \mathrm{~cm}^{2}$, bandwidth $=60 \mathrm{kHz}$, matrix size $=128 \times 128$, isotropic in-plane resolution $=0.273 \mathrm{~mm}$, slice thickness $=1.0 \mathrm{~mm}, 14$ slices, number of averages $=1$ and fat suppression set to off. $T_{2}$ relaxation times were calculated by fitting a mono-exponential function to the average signal found in a manually drawn ROI on the thigh muscle. $\mathrm{T}_{2} \mathrm{w}$ images were acquired using a rapid acquisition with relaxation enhancement (RARE) sequence at a repetition time 


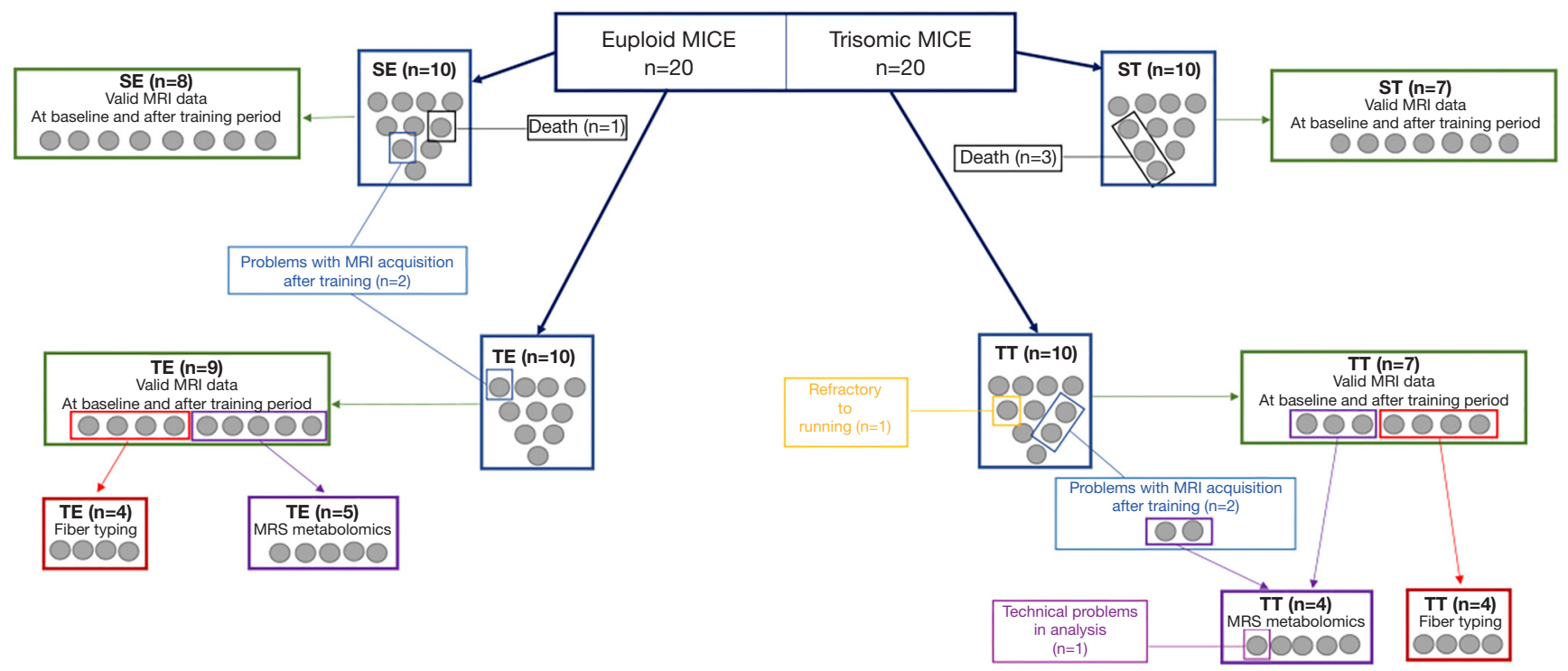

Figure 1 Schematic overview of the whole experiment. Nine mice dropped out the MRI experiment due to death (ST, $\mathrm{n}=3$; SE, $\mathrm{n}=1$ ), refractoriness to running (TT, n=1), problems during MRI acquisition (TT, n=2; SE, n=1; TE, n=1). One TT mouse dropped out the MRS metabolomics analysis due to technical problems. MRI, magnetic resonance imaging; ST, sedentary trisomic; SE, sedentary euploid; TT, training trisomic; TE, training euploid; MRS, magnetic resonance spectroscopy.

$=5,000 \mathrm{~ms}$, echo time $=56 \mathrm{~ms}$, field of view $=3.5 \times 3.5 \mathrm{~cm}^{2}$, bandwidth $=50 \mathrm{kHz}$, matrix size $=192 \times 192$, isotropic inplane resolution $=0.182 \mathrm{~mm}$, slice thickness $=1.0 \mathrm{~mm}$, 14 slices, RARE factor $=8$; number of averages $=1$ and fat suppression set to off.

Four 1-mm thick axial sections of the proximal hindlimbs, acquired in each mouse at baseline and at the endpoint (Figure 2), were selected using anatomical landmarks (proximal, hip joint; distal, condyles). The cross-sectional areas of the proximal hindlimb skeletal muscle \{i.e., proximal hindlimb muscles plus femur bone minus proximal hindlimb adipose tissue under the complex superficial/deep (lata) fascia (for the sake of simplicity referred to as fascia in the following) [(subfascia) adipose tissue] and femur bone\}, proximal hindlimb subfascia adipose tissue, and subcutaneous adipose tissue (i.e., total sectional area minus proximal hindlimb muscle + bone area + area occupied by other structures), were measured using the ImageJ software (National Institutes of Health, USA) by manually drawing ROIs on $\mathrm{T}_{2} \mathrm{w}$ RARE images. Tissue volumes, expressed as $\mathrm{mm}^{3}$, were obtained according to the Cavalieri's principle. The skeletal muscle volume of the hindlimbs was considered the main outcome of the study.

\section{MRS metabolomics}

At the endpoint, Ts65Dn mice were deeply anesthetized with tribromoethanol and killed by cervical dislocation. Quadriceps muscles of TE $(n=5)$ and TT $(n=5)$ mice for a total of 10 animals, were immediately dissected out after sacrifice, blotted on filter paper, weighed, and frozen in liquid nitrogen. Frozen specimens were then freeze-dried, ground to powder, and extracted in a mixture of methanol and chloroform as previously described (5). The resulting aqueous and organic fractions were dried and stored at $-80^{\circ} \mathrm{C}$ until analysis.

The spectra of aqueous and organic fractions were recorded at $27{ }^{\circ} \mathrm{C}$ on a Bruker AVANCE $600 \mathrm{NMR}$ spectrometer operating at the proton frequency of $600.13 \mathrm{MHz} .{ }^{1} \mathrm{H}$ spectra were referenced to the methyl group signal of 3-(trimethylsilyl)-propionic-2,2,3,3- $\mathrm{d}_{4}$ acid sodium salts (TSP; $\delta=0.00 \mathrm{ppm}$ ) in $\mathrm{D}_{2} \mathrm{O}$, and to the $\mathrm{CH} 3$ signal of TMS in $\mathrm{CDCl}_{3} / \mathrm{CD}_{3} \mathrm{OD}$, respectively. Assignment of spectra was conducted as previously described (14). In the case of aqueous samples, the integral values were normalized to the integral of the standard TSP (methyl group signal) set to 100 and divided by sample wet weight and used for quantitative analysis. In the case of $\mathrm{CDCl}_{3} / \mathrm{CD}_{3} \mathrm{OD}$ spectra, 

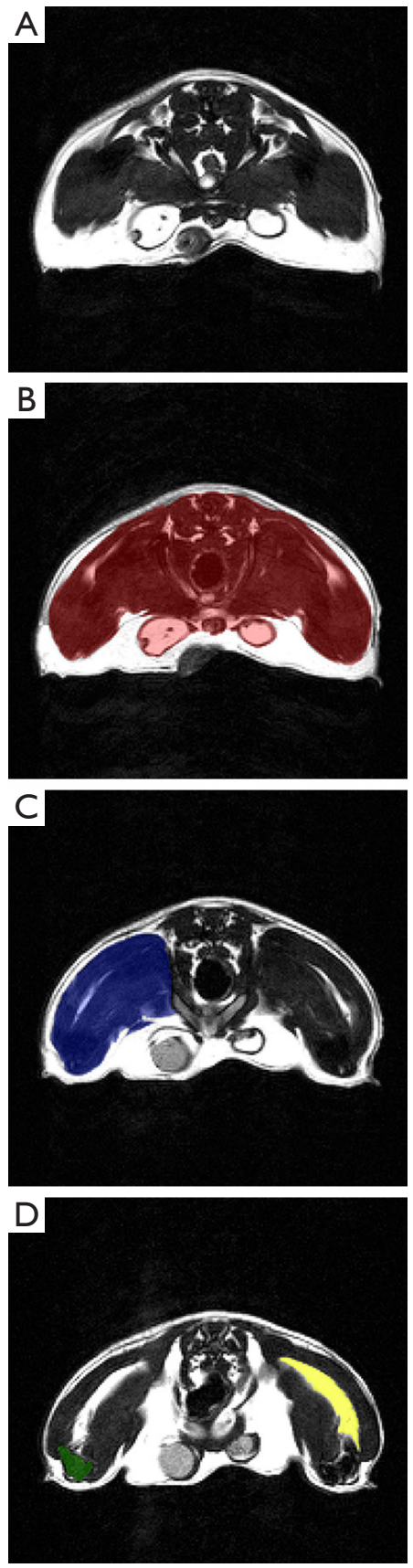

Figure 2 Representative Ts65Dn hindlimbs MRI images taken at $20 \%$ (A), 40\% (B), 60\% (C), and 80\% (D) distance from the hip joint to illustrate the morphometric variables measured in this study. (A) Total sectional area, used for calculation of subcutaneous adipose tissue area. (B) Subcutaneous adipose tissue area is total sectional area minus the proximal hindlimb muscles + bone area and other structures (red area). (C) Proximal hindlimb muscles + bone area (blue area). (D) Femur bone area (green area), proximal hindlimb intermuscular adipose tissue area (yellow area). MRI, magnetic resonance imaging. a previously described procedure was followed (14).

\section{Fiber typing}

At the endpoint, anesthetized mice were perfused transcardially with $0.1 \mathrm{M}$ phosphate buffer solution (PBS) followed by 4\% paraformaldehyde in PBS. After perfusion, the quadriceps muscle was quickly removed and cut transversely at mid-length. Samples of about $1 \mathrm{~mm}^{3}$ were further placed in $4 \%$ paraformaldehyde and $0.2 \%$ glutaraldehyde in $0.1 \mathrm{M}$ PBS for $2 \mathrm{~h}$ at $4{ }^{\circ} \mathrm{C}$. After fixation, samples were washed in PBS, treated with $0.5 \mathrm{M} \mathrm{NH} 4 \mathrm{Cl}$ solution in PBS for $45 \mathrm{~min}$ at $4{ }^{\circ} \mathrm{C}$ to block free aldehyde groups, dehydrated in graded concentrations of ethanol at room temperature, and embedded in LR-White resin. Two $\mu$ m-thick cross-sections of LR-White embedded muscles from TE $(n=4)$ and TT $(n=4)$ mice, for a total of 8 animals, were submitted to immunohistochemical procedures to distinguish fast and slow fibers (5) using a mouse monoclonal antibody recognizing the heavy chain of skeletal fast fiber myosin (clone MY-32, SigmaAldrich, Buchs, Switzerland) diluted 1:200 in PBS; the antigen-antibody complex was revealed with an Alexa 488 conjugated antibody against mouse IgG (Molecular Probes, Invitrogen, Milan, Italy). Micrographs were taken with an Olympus BX51 microscope equipped with a $100 \mathrm{~W}$ mercury lamp and recorded in an Olympus Camedia C-5050 digital camera. In immunolabeled samples, the percentage of fast and slow muscle fibers was calculated on a minimum of 100 myofibers per hindlimb, with at least 650 myofibers measured per group (trisomic and euploid).

\section{Statistical analysis}

A priori analysis for the sample size for the MRI experiment was carried out with $\mathrm{G}^{*}$ Power Software (v.3.1) using the following settings: effect size $f=0.25$, alpha $=0.05$, power $=0.80$, four groups, and two measurement times. Results showed that a total of 24 mice was needed.

Data are presented as mean \pm standard error of the mean (SEM). For MRI measurements, the normality of data was assessed with the Shapiro-Wilk test. One-way ANOVA was used for group-group comparison at baseline; twoway ANOVA (factor: training; measurement time point) was used for assessing the effect of physical exercise and time of measurement (i.e., baseline and endpoint) as well as their interaction in the four groups of mice. Effect size (eta squared) was calculated and rated according 
to Cohen, 1988 (15): 0.01 small, 0.06 medium, 0.14 large. The two-tailed Spearman correlation coefficient (rho) was used to assess the association between variables. Partial correlations were also calculated using body mass as the covariate. When comparing results of MRS metabolomics and fiber type analysis, the non-parametric Mann-Whitney test was used due to the limited number of mice. Statistical significance was set at alpha $\leq 0.05$. The IBM-SPSS (v.25) statistical package was used for all analyses.

\section{Results}

The mean age of mice used in this experiment was $9 \pm 0.64$ (range, 6-12) months.

Body weight was higher in euploid $(\mathrm{n}=17) v s$. trisomic $(\mathrm{n}=14)$ mice at baseline $(46.4 \pm 1.2$ and $40.6 \pm 0.97 \mathrm{~g}$, respectively; $\mathrm{F}=13.289, \mathrm{P}=0.001$, eta squared: medium) also after adjusting for age $(\mathrm{P}<0.001)$ and remained so at endpoint $(\mathrm{P}<0.001)$. A priori power analysis demonstrated that a minimum of 24 mice was needed to power the study. To account for the possible drop-out of mice a total of 40 mice (ten per each group: TT, TE, ST, SE) started the experiment. Nine mice dropped out the MRI experiment due to death (trisomic, $\mathrm{n}=3$; euploid, $\mathrm{n}=1$ ), refractoriness to running (trisomic, $\mathrm{n}=1$; euploid, $\mathrm{n}=0$ ), problems during MRI acquisition (trisomic, $\mathrm{n}=2$; euploid, $\mathrm{n}=2$ ). Valid, complete MRI results were obtained for 31 mice (17 euploids, 14 trisomics) and used in the analysis (Figure 1). All mice in the sample were able to correctly carry out the physical training protocol. Group distribution of mice was as follows: SE, $n=8$; ST, $n=7$; TE, $n=9$; TT, $n=7$. Therefore, according to the a priori analysis, the study was sufficiently powered, with a similar number of mice in each group.

\section{MRI and in vivo morphometry}

The volume of proximal hindlimb skeletal muscle, proximal hindlimb subfascia adipose tissue, subcutaneous adipose tissue, and $T_{2}$ was not significantly different in the four groups of mice (SE, $\mathrm{n}=8$; TE, $\mathrm{n}=9$; $\mathrm{ST}, \mathrm{n}=7$; TT, $\mathrm{n}=7$ ) at baseline $(\mathrm{F}=0.058, \mathrm{P}=0.812 ; \mathrm{F}=2.040, \mathrm{P}=0.164 ; \mathrm{F}=1.874$, $\mathrm{P}=0.182 ; \mathrm{F}=0.647, \mathrm{P}=0.428 ; \mathrm{F}=0.142, \mathrm{P}=0.709$ respectively; eta squared small for all, Table 1). After adjusting for age, all differences remained non-significant (F ranging 0.000-2.678, $\mathrm{P}$ ranging 0.113-0.990). Two-way ANOVA showed no significant difference in the four groups of mice for both training and measurement time-point as well as their interaction (eta squared small to medium). Similar findings were found after adjusting for body mass or age. Correlation analysis carried out in the whole sample of mice at baseline showed a statistically significant association between body mass and subcutaneous adipose tissue volume (Figure $3 \mathrm{~A}$, $\mathrm{r}=0.454, \mathrm{P}=0.010)$ as well as, at the limits of significance, proximal hindlimb subfascia adipose tissue volume (Figure $3 B$, $\mathrm{r}=0.331, \mathrm{P}=0.069$ ). No statistically significant correlation was found between body mass and proximal hindlimb skeletal muscle volume (Figure 3C, $\mathrm{r}=0.005, \mathrm{P}=0.979$ ). Subcutaneous and proximal hindlimb subfascia adipose tissue volumes positively correlated, but the correlation was not statistically significant (Figure 3D, $\mathrm{r}=0.230, \mathrm{P}=0.214$ ).

\section{MRS metabolomics}

Several intermediate metabolism compounds (succinic acid, lactic acid, acetic acid, pyruvic acid), amino acids (e.g., leucine, isoleucine, valine, alanine, tyrosine), nucleosides (NAD+), as well as key molecules for muscle energetics ( $\alpha$-glucose, creatine/phosphocreatine), were unambiguously identified and quantified in the aqueous fraction as shown previously (5). In TE ( $\mathrm{n}=5)$ vs. TT $(\mathrm{n}=4$; one sample was discarded due to technical problems; Figure 1) mice, the aqueous metabolites valine $(0.51 \pm 0.080$ vs. $0.72 \pm 0.127)$, isoleucine $(0.20 \pm 0.048$ vs. $0.31 \pm 0.071)$, leucine $(1.68 \pm 0.128$ vs. $2.32 \pm 0.540)$ and $\alpha$-glucose $(1.27 \pm 0.216$ vs. $1.59 \pm 0.111)$ were present in lower amounts per unit wet tissue $(\mathrm{P}=0.027$; $\mathrm{P}=0.014 ; \mathrm{P}=0.050 ; \mathrm{P}=0.027$, respectively).

At endpoint, the creatine to phosphocreatine ratio $(\mathrm{Cr} / \mathrm{PCr})$ was lower in the skeletal muscle of euploid $v s$. trisomic mice at the limit of statistical significance (81.39 vs. 83.87, $\mathrm{P}=0.073)$.

\section{Fiber typing}

The percentage of slow twitch fibers was not significantly different in TE $(\mathrm{n}=4) v s$. TT $(\mathrm{n}=4)$ mice: $(4.75 \pm 4.26$ vs. $2.25 \pm 1.54, \mathrm{Z}=-0.367, \mathrm{P}=0.712)$.

\section{Discussion}

Mitigation of the skeletal muscle deficit of DS would have a strong impact on the quality of life of affected people (16). Physical exercise has been shown to be beneficial on several outcomes in human DS $(17,18)$. In Ts65Dn mice, physical exercise has been shown to improve several neurologic characteristics (19-22). In this work, we explored for the first time the in vivo effect of physical exercise, a well-known tool 
Table 1 MRI-measured variables in the proximal hindlimbs of Ts65Dn mice at baseline and the end of the 4-week experimental period (endpoint)

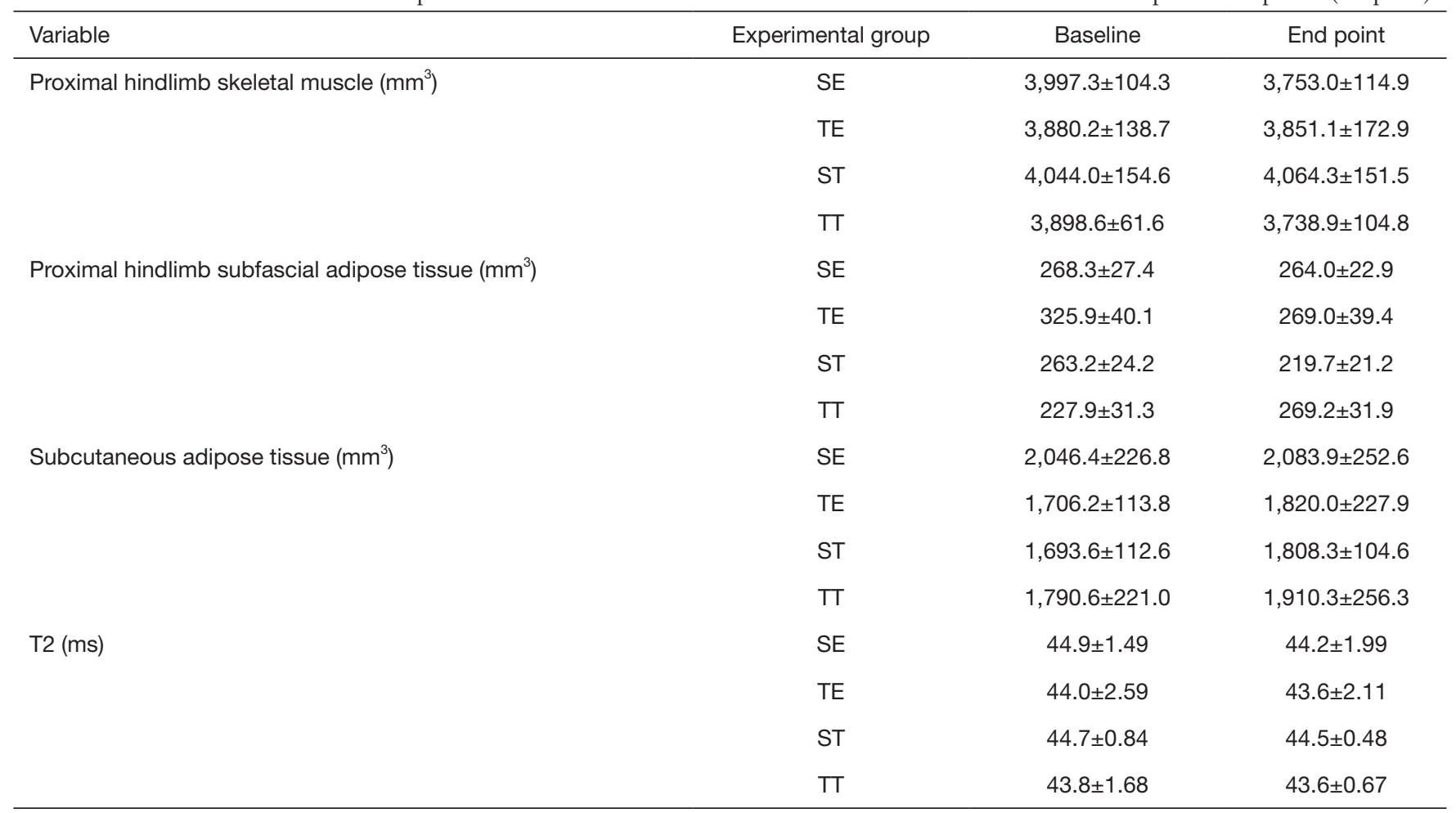

Data are mean \pm SEM. No statistically significant difference was found within groups at baseline and endpoint, nor between baseline and endpoint in each group. SE, $n=8 ; T E, n=9 ; S T, n=7 ; T, n=7$. MRI, magnetic resonance imaging; SE, sedentary euploid; TE, training euploid; ST, sedentary trisomic; TT, training trisomic; SEM, standard error of the mean.

for improving skeletal muscle condition, in a current animal model of DS. While we cannot exclude that the adapted physical training protocol we adopted was insufficient to fully highlight the expected effect of long-term exercise on skeletal muscle, previous work from our laboratory showed that such adapted physical exercise was able to positively affect both brain (13) and skeletal muscle (23) outcomes in old (i.e., frail) mice.

At baseline, trisomic mice showed lower body mass than the euploid, consistently with previous findings (24); however, proximal hindlimbs skeletal muscle volume did not show statistically significant differences, suggesting that difference in body mass is due to lower volume of organs other than muscles, the main component of hindlimbs. This is supported by the absence of correlation between body mass and proximal hindlimb skeletal muscle volume (Figure 3C) in the whole group of mice (trisomic + euploid) as well as the positive correlation between body mass and the volume of proximal hindlimb subcutaneous adipose tissue (Figure 3A). Moreover, subfascia and subcutaneous adipose tissue volumes were positively, albeit not statistically significantly, correlated. These data suggest that changes in both skeletal muscle and adipose tissue are not likely to explain the difference in body mass between euploid and trisomic mice. $T_{2}$ relaxation time, which may be altered in animal models of dystrophy (25) were similar as well. Indeed, the $T_{2}$ values of skeletal muscle here measured are higher compared to literature (26); however, the sequence adopted in this study had fat suppression set to off to be sensitive to fat. Accordingly, the muscular fat could have boosted the global voxel signal (being the $T_{2}$ of fat generally higher than that of muscle) and hence generate increased $\mathrm{T}_{2}$ values of skeletal muscle in both euploid and trisomic mice. Taken together, literature findings and data presented herein strongly suggest that structural and functional changes in the skeletal muscle are not a major cause for the locomotor deficit observed in DS. Interestingly, adapted physical exercise did not affect skeletal muscle and adipose tissue volumes in hindlimbs nor $T_{2}$ values, independently of age. Moreover, the proportion of slow-twitch fibers was not affected by adapted physical exercise. Further, metabolomic data suggested that adapted physical exercise stimulates the 

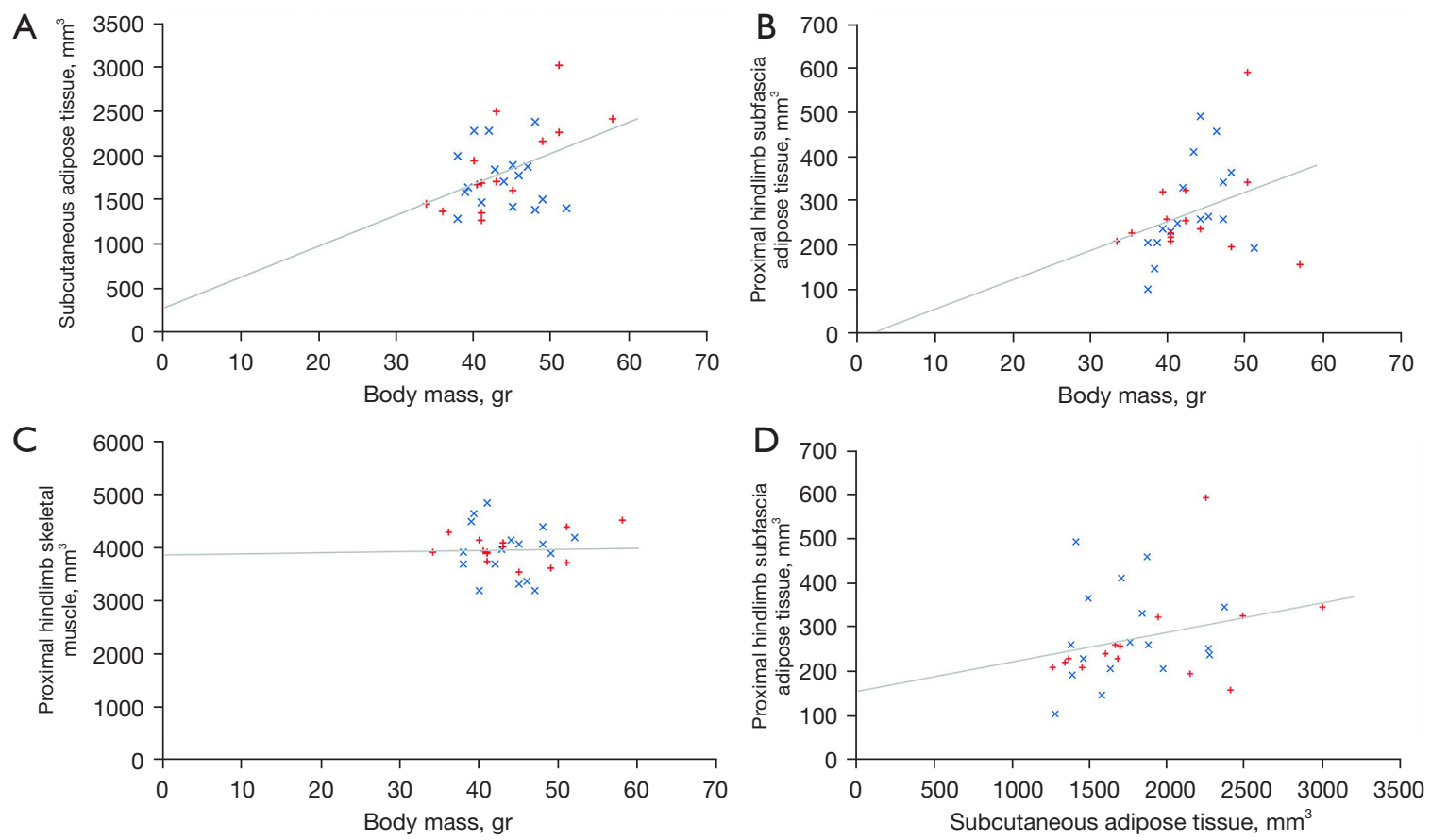

Figure 3 Correlation analysis (Pearson's $r$ ) in the whole sample of Ts65Dn mice (euploid, blue $\times$; trisomic, red +; $n=31$ ) at baseline. (A) Positive correlation $(r=0.454, \mathrm{P}=0.010)$ between body mass and subcutaneous adipose tissue volume. (B) Positive correlation at the limit of statistical significance between body mass and proximal hindlimb subfascia adipose tissue volume ( $\mathrm{r}=0.331, \mathrm{P}=0.069)$. (C) Lack of correlation between body mass and proximal hindlimb skeletal muscle volume ( $\mathrm{r}=0.005, \mathrm{P}=0.979)$. (D) Positive non statistically significant correlation between subcutaneous and proximal hindlimb subfascia adipose tissue volumes $(r=0.230, \mathrm{P}=0.214)$.

metabolic pathways typically triggered by training better in euploid than trisomic mice. In fact, lower levels of valine, isoleucine, and leucine were found in euploid $v s$. trisomic mice at endpoint. This is possibly associated with the increasing energy expenditure induced by physical exercise, which is reflected in the catabolism of the branched-chain amino acids valine, isoleucine, leucine which, in turn, are to be oxidated to contribute to the energy metabolism (27). Instead, a tendency was found of the $\mathrm{Cr} / \mathrm{PCr}$ to be lower in the skeletal muscle of euploid $v s$. trisomic mice at endpoint suggesting better ability to restore energy storage in the former. It should be kept in mind that measurements were carried out at endpoint i.e., three days after completion of the training period, in a basal state. Further studies using in vivo ${ }^{31} \mathrm{PMRS}$ would allow better understanding of the in vivo acute effect of physical exercise in the DS skeletal muscle.

A limit of this study is that we did not measure the muscular fat fraction in the proximal hindlimb muscles. Accordingly, we could not make any inference about the effect of adapted physical exercise on that variable, which has been associated with decreasing muscle function in peripheral muscular disease (28). Future work will help clarifying this issue.

Overall, the current findings suggest that (I) central factors and/or neural activation play an important role in the muscular deficit of DS. This is consistent with the cerebellar deficits observed in DS (inclusive of a reduced number of cells) (29), the impairment in neuronal connectivity and cortex structure (30), as well as the lower motor conduction velocity of the peripheral nerve (31) and the neuroanatomical defects affecting the neuromuscular junction (32); (II) exercise-associated energy metabolism is to some extent hampered in trisomic muscle. Further research is needed to verify if energy metabolism is a cue to an intrinsic metabolic deficit in the DS skeletal muscle.

\section{Acknowledgments}

We thank Dr. Elena Nicolato and the Centro Piattaforme Tecnologiche (CPT) of the University of Verona for assistance with MRI. 
Funding: This work was supported by the University of Verona (Fondo Unico per la Ricerca to CZ and MM).

\section{Footnote}

Reporting Checklist: The authors have completed the ARRIVE reporting checklist. Available at https://dx.doi. org/10.21037/qims-21-729

Conflicts of Interest: All authors have completed the ICMJE uniform disclosure form (available at https://dx.doi. org/10.21037/qims-21-729). The authors have no conflicts of interest to declare.

Ethical Statement: The authors are accountable for all aspects of the work in ensuring that questions related to the accuracy or integrity of any part of the work are appropriately investigated and resolved. The study was approved by national committee board of the Italian Ministry of Health (ref.: 538/2015-PR), in compliance with the Italian Ministry of Health (DL March 4, 2014, n. 26) and the European Communities Council (Directive 63/2010/EU of the European Parliament and of the Council) guidelines for the care and use of animals.

Open Access Statement: This is an Open Access article distributed in accordance with the Creative Commons Attribution-NonCommercial-NoDerivs 4.0 International License (CC BY-NC-ND 4.0), which permits the noncommercial replication and distribution of the article with the strict proviso that no changes or edits are made and the original work is properly cited (including links to both the formal publication through the relevant DOI and the license). See: https://creativecommons.org/licenses/by-nc-nd/4.0/.

\section{References}

1. Korenberg JR, Chen XN, Schipper R, Sun Z, Gonsky R, Gerwehr S, Carpenter N, Daumer C, Dignan P, Disteche C. Down syndrome phenotypes: the consequences of chromosomal imbalance. Proc Natl Acad Sci U S A 1994;91:4997-5001.

2. Cioni M, Cocilovo A, Di Pasquale F, Araujo MB, Siqueira CR, Bianco M. Strength deficit of knee extensor muscles of individuals with Down syndrome from childhood to adolescence. Am J Ment Retard 1994;99:166-74.

3. Davisson MT, Schmidt C, Reeves RH, Irving NG, Akeson EC, Harris BS, Bronson RT. Segmental trisomy as a mouse model for Down syndrome. Prog Clin Biol Res 1993;384:117-33.

4. Cisterna B, Costanzo M, Scherini E, Zancanaro C, Malatesta $M$. Ultrastructural features of skeletal muscle in adult and aging Ts65Dn mice, a murine model of Down syndrome. Muscles Ligaments Tendons J 2014;3:287-94.

5. Cisterna B, Sobolev AP, Costanzo M, Malatesta M, Zancanaro C. Combined Microscopic and Metabolomic Approach to Characterize the Skeletal Muscle Fiber of the Ts65Dn Mouse, A Model of Down Syndrome. Microsc Microanal 2020;26:1014-23.

6. Zancanaro C, Mariotti R, Perdoni F, Nicolato E, Malatesta M. Physical training is associated with changes in nuclear magnetic resonance and morphometrical parameters of the skeletal muscle in senescent mice. Eur J Histochem 2007;51:305-10.

7. Bontempi P, Busato A, Bonafede R, Schiaffino L, Scambi I, Sbarbati A, Mariotti R, Marzola P. MRI reveals therapeutical efficacy of stem cells: An experimental study on the SOD1(G93A) animal model. Magn Reson Med 2018;79:459-69.

8. Charles JP, Cappellari O, Spence AJ, Hutchinson JR, Wells DJ. Musculoskeletal Geometry, Muscle Architecture and Functional Specialisations of the Mouse Hindlimb. PLoS One 2016;11:e0147669.

9. Sugimoto D, Bowen SL, Meehan WP 3rd, Stracciolini A. Effects of Neuromuscular Training on Children and Young Adults with Down Syndrome: Systematic Review and Meta-Analysis. Res Dev Disabil 2016;55:197-206.

10. Costa AC, Walsh K, Davisson MT. Motor dysfunction in a mouse model for Down syndrome. Physiol Behav 1999;68:211-20.

11. Sanders NC, Williams DK, Wenger GR. Does the learning deficit observed under an incremental repeated acquisition schedule of reinforcement in Ts65Dn mice, a model for Down syndrome, change as they age? Behav Brain Res 2009;203:137-42.

12. Reinholdt LG, Ding Y, Gilbert GJ, Czechanski A, Solzak JP, Roper RJ, Johnson MT, Donahue LR, Lutz C, Davisson MT. Molecular characterization of the translocation breakpoints in the Down syndrome mouse model Ts65Dn. Mamm Genome 2011;22:685-91.

13. Fattoretti P, Malatesta M, Cisterna B, Milanese C, Zancanaro C. Modulatory Effect of Aerobic Physical Activity on Synaptic Ultrastructure in the Old Mouse Hippocampus. Front Aging Neurosci 2018;10:141.

14. Sobolev AP, Mannina L, Costanzo M, Cisterna B, Malatesta M, Zancanaro C. Age-related changes in skeletal 
muscle composition: A pilot nuclear magnetic resonance spectroscopy study in mice. Exp Gerontol 2017;92:23-7.

15. Parker RI, Hagan-Burke S. Useful effect size interpretations for single case research. Behav Ther 2007;38:95-105.

16. Jover M, Ayoun C, Berton C, Carlier M. Specific grasp characteristics of children with trisomy 21. Dev Psychobiol 2010;52:782-93.

17. Martínez-Espinosa RM, Molina Vila MD, Reig GarcíaGalbis M. Evidences from Clinical Trials in Down Syndrome: Diet, Exercise and Body Composition. Int J Environ Res Public Health 2020;17:4294.

18. Li C, Chen S, Meng How Y, Zhang AL. Benefits of physical exercise intervention on fitness of individuals with Down syndrome: a systematic review of randomizedcontrolled trials. Int J Rehabil Res 2013;36:187-95.

19. Llorens-Martín MV, Rueda N, Tejeda GS, Flórez J, Trejo JL, Martínez-Cué C. Effects of voluntary physical exercise on adult hippocampal neurogenesis and behavior of Ts65Dn mice, a model of Down syndrome. Neuroscience 2010;171:1228-40.

20. Kida E, Rabe A, Walus M, Albertini G, Golabek AA. Long-term running alleviates some behavioral and molecular abnormalities in Down syndrome mouse model Ts65Dn. Exp Neurol 2013;240:178-89.

21. Walus M, Kida E, Rabe A, Albertini G, Golabek AA. Widespread cerebellar transcriptome changes in Ts65Dn Down syndrome mouse model after lifelong running. Behav Brain Res 2016;296:35-46.

22. Parrini M, Ghezzi D, Deidda G, Medrihan L, Castroflorio E, Alberti M, Baldelli P, Cancedda L, Contestabile A. Aerobic exercise and a BDNF-mimetic therapy rescue learning and memory in a mouse model of Down syndrome. Sci Rep 2017;7:16825.

23. Cisterna B, Giagnacovo M, Costanzo M, Fattoretti P, Zancanaro C, Pellicciari C, Malatesta M. Adapted physical exercise enhances activation and differentiation potential of satellite cells in the skeletal muscle of old mice. J Anat 2016;228:771-83.

24. Fructuoso M, Rachdi L, Philippe E, Denis RG, Magnan

Cite this article as: Cisterna B, Bontempi $\mathrm{P}$, Sobolev AP, Costanzo M, Malatesta M, Zancanaro C. Quantitative magnetic resonance characterization of the effect of physical training on skeletal muscle of the Ts65Dn mice, a model of Down syndrome. Quant Imaging Med Surg 2022;12(3):2066-2074. doi: 10.21037/qims-21-729
C, Le Stunff H, Janel N, Dierssen M. Increased levels of inflammatory plasma markers and obesity risk in a mouse model of Down syndrome. Free Radic Biol Med 2018;114:122-30.

25. Park JS, Vohra R, Klussmann T, Bengtsson NE, Chamberlain JS, Lee D. Non-invasive tracking of disease progression in young dystrophic muscles using multiparametric MRI at 14T. PLoS One 2018;13:e0206323.

26. Bryant ND, Li K, Does MD, Barnes S, Gochberg DF, Yankeelov TE, Park JH, Damon BM. Multi-parametric MRI characterization of inflammation in murine skeletal muscle. NMR Biomed 2014;27:716-25.

27. Rennie MJ. Influence of exercise on protein and amino acid metabolism. In: Rowell LB, Shepherd JT. editors. Handbook of Physiology: Section 12: Exercise: Regulation and Integration of Multiple Systems. Bethesda, MD, USA: American Physiological Society, 1996:995-1035.

28. Barnard AM, Willcocks RJ, Finanger EL, Daniels MJ, Triplett WT, Rooney WD, Lott DJ, Forbes SC, Wang DJ, Senesac CR, Harrington AT, Finkel RS, Russman BS, Byrne BJ, Tennekoon GI, Walter GA, Sweeney HL, Vandenborne K. Skeletal muscle magnetic resonance biomarkers correlate with function and sentinel events in Duchenne muscular dystrophy. PLoS One 2018;13:e0194283.

29. Guidi S, Ciani E, Bonasoni P, Santini D, Bartesaghi R. Widespread proliferation impairment and hypocellularity in the cerebellum of fetuses with down syndrome. Brain Pathol 2011;21:361-73.

30. Anderson JS, Nielsen JA, Ferguson MA, Burback MC, Cox ET, Dai L, Gerig G, Edgin JO, Korenberg JR. Abnormal brain synchrony in Down Syndrome. Neuroimage Clin 2013;2:703-15.

31. Phillips AC, Sleigh A, McAllister CJ, Brage S, Carpenter TA, Kemp GJ, Holland AJ. Defective mitochondrial function in vivo in skeletal muscle in adults with Down's syndrome: a 31P-MRS study. PLoS One 2013;8:e84031.

32. Yarom R, Sherman Y, Sagher U, Peled IJ, Wexler MR, Gorodetsky R. Elevated concentrations of elements and abnormalities of neuromuscular junctions in tongue muscles of Down's syndrome. J Neurol Sci 1987;79:315-26. 